\title{
BMJ Open Cross-sectional study of correlates and prevalence of functional and high-risk multimorbidity in an academic HIV practice in New York City
}

\author{
Eugenia Siegler (D) , ${ }^{1}$ Jerad Moxley (D) , ${ }^{1}$ Elizabeth Mauer (D) , ${ }^{2,3}$ \\ Marshall Glesby (iD)
}

To cite: Siegler E, Moxley J, Mauer E, et al. Crosssectional study of correlates and prevalence of functional and high-risk multimorbidity in an academic HIV practice in New York City. BMJ Open 2021;11:e047199. doi:10.1136/ bmjopen-2020-047199

- Prepublication history and additional supplemental material for this paper are available online. To view these files, please visit the journal online. (http://dx.doi.org/10.1136/ bmjopen-2020-047199).

Received 21 November 2020 Accepted 27 July 2021

\section{Check for updates}

(C) Author(s) (or their employer(s)) 2021. Re-use permitted under CC BY-NC. No commercial re-use. See rights and permissions. Published by BMJ.

${ }^{1}$ Division of Geriatrics and Palliative Medicine, Weill Cornell Medicine, New York, New York, USA

2Department of Population Health Sciences, Weill Cornell Medicine, New York, New York, USA

${ }^{3}$ Tempus Labs, Inc, New York, New York, USA

${ }^{4}$ Division of Infectious Diseases, Weill Cornell Medicine, New

York, New York, USA

Correspondence to

Dr Eugenia Siegler; els2006@med.cornell.edu

\section{ABSTRACT}

Objectives People with HIV have high levels of multimorbidity, but studies often focus on high-risk comorbidities such as hypertension or coronary artery disease. We examined both high-risk and functional comorbidities in an ethnically diverse clinic population to compare the prevalence of comorbidities and different patterns of multimorbidity.

Design Retrospective cross-sectional study.

Setting University-based primary care HIV clinic with two locations in New York City.

Participants Patients who had been seen by a physician at least once between 1 June 2016 and 31 May 2017.

Primary and secondary outcome measures Data regarding demographics, diagnoses and lab values were downloaded in a one-time data import from the electronic medical record. Comorbidities were classified as high-risk (with major impact on mortality) or functional (with major impact on function), and multimorbidity was determined for both classes in the total sample of 2751. Factors associated with high-risk and functional multimorbidity were determined first through bivariate analysis and then through multivariable median regression in 2013 patients with complete data.

Results Median age was 52 years (IQR 43-59). Cisgendered women comprised $24.6 \%$ of the sample, and $31.7 \%$ were African-American. Both functional and high-risk comorbidities were common and risk increased with age. Among those 75 and older, median number of both functional and high-risk comorbidities was 3 (IQR 2-4). High-risk comorbidities were associated with age $(p<0.001)$, more years with an HIV diagnosis $(p<0.001)$ and being an African-American $(p<0.001)$. Associated with a higher number of functional comorbidities were age $(p<0.001)$, being a cisgender female $(p<0.001)$, being Hispanic $(p=0.01)$ and more years with an HIV diagnosis $(p<0.001)$.

Conclusions Comorbidities with functional impact increase with age in parallel to those with a more direct impact on mortality and should be assessed and monitored, especially as the population with HIV ages.

\section{INTRODUCTION}

With the advent of effective anti-retroviral medication, people are living with HIV as a
Strengths and limitations of this study

It examines both functional and high-risk multimorbidity in older people with HIV.

- The study population is large and diverse.

- It distinguishes between age-related and non-agerelated comorbidities in this population.

- It is from a single academic medical centre in New York City.

- It is based on extraction of data from an electronic health record.

chronic disease. Although many people with HIV can live to near-normal life spans, ${ }^{1}$ they are at higher risk than their HIV negative counterparts for comorbidities ${ }^{2-5}$ like heart disease, ${ }^{6}$ bone disease ${ }^{7}$ and neuropsychiatric illnesses like depression, ${ }^{8}$ as well as geriatric syndromes like falls and frailty. ${ }^{9}$ Geriatric assessment, which evaluates the impact of medical and psychosocial factors on individual's function, has been proposed as a way to help optimise care of people with HIV as they age ${ }^{10}$ WHO supports this focus on function, defining healthy ageing as 'the process of developing and maintaining the functional ability that enables well-being in older age'. ${ }^{11}$

Multimorbidity, which has been defined as the presence of two or more chronic conditions,${ }^{12}$ is increased in the population with HIV. ${ }^{13} 14$ Multimorbidity has been assessed in a wide variety of ways, with instruments measuring anywhere from 4 to 102 different conditions. ${ }^{15}$ Recent studies have identified multimorbidity clusters ${ }^{16}$ as a way of generating hypotheses regarding disease aetiology and risk. The focus of these studies has largely been on illnesses with significant impact on mortality. In ageing populations in particular, mortality impact is insufficient; it is important to examine multimorbidity in terms of functional impact, as well. 
Many of the studies documenting multimorbidity have been conducted as prospective cohorts using very selective populations. The advent of the electronic health record (EHR) has enabled providers to maintain a more comprehensive past medical history and problem list, and despite its drawbacks, ${ }^{17}$ has provided opportunities to expand study populations to a more representative sample of people with HIV in the community who are receiving medical care. We took advantage of such a system to study the characteristics of the patients who attended a dedicated HIV Clinic, the Centre for Special Studies at the Weill Cornell Campus of New York Presbyterian Hospital. This clinic, which dates from the early days of the AIDS epidemic, provides care for approximately 3000 people who have HIV throughout the New York City metropolitan area. This enables the study of a large, diverse group of people with HIV without the selection bias associated with studies of voluntary study participants. Our objectives for this study were to examine the prevalence of various comorbidities in a real-world sample, and to evaluate the relationship between functionally important and high-risk comorbidities, HIV parameters and age.

\section{METHODS}

This study was designed to determine the distribution and correlates of high-risk and functional comorbidities in a large population with HIV. Information from all patients who had been seen by a physician at least once at the Centre for Special Studies between 1 June 2016 and 31 May 2017 was downloaded from the EHR (EPIC Hyperspace 2019) into an Excel spreadsheet. Data of interest included demographics, socioeconomic conditions as documented in the social work notes, medications, medical history, surgical history, problem list, geriatric scales when available, vital signs, lab data and miscellaneous items (eg, whether the patient had seen one of the clinic's four psychiatrists in the past year).

\section{Patient and public involvement}

There was no patient/public involvement in the design or execution of this study.

The presence or absence of a comorbidity was determined by checking the problem list, past medical history or surgical history for specific International Classification of Disease (ICD)-10 codes, or in the case of renal disease and diabetes, searching for specific lab values. The criteria for each of the comorbidities is included in online supplemental digital content table 1. Data were analysed via SPSS (IBM SPSS Statistics for Windows, V.25). When medians are reported, IQR are presented as the 25th and 75th percentiles.

Comorbidities were classified in several ways. We first used a very inclusive definition, including all of the comorbidities that were in the original database. We also used more specific measures, one focused on diseases that had a high impact on mortality, termed 'high-risk' and the other focused on diseases that had a higher impact on functional impairment (eg, walking or carrying out tasks of daily living), termed 'functional'. In the absence of a literature to categorise them, these comorbidities were grouped by consensus of two of the study authors (ELS, MJG) prior to the analysis. The classification for each of the comorbidities is presented in abbreviated fashion in table 1. More detail is provided in online supplemental digital content table 2 . Three of the comorbidities (cerebrovascular disease, lipohypertrophy/lipoatrophy and obesity) were felt to have significant high-risk and functional implications, and were included in both groups.

Sex was divided into male and female based on selfidentification; transgender status was coded based on the person either explicitly noting themselves as being transgender in their gender identity or a dissociation between the coding for their sex assigned at birth and their gender identity. For clarity in data presentation, we divided age into the following categories: $18-49,50-64$, $65-74$ and $75+$, but age was used as a continuous variable for the statistical analyses. Spearman correlation values were calculated for continuous variables and the pointbiserial method was used for categorical values. $\mathrm{P}$ values are reported in the table for each variable; those with multiple categories were calculated using multinomial logistic regression to obtain a $\chi^{2}$ statistic.

Because the distribution of the number of comorbidities in this study (see online supplemental digital content figure 1) was skewed leftward and did not approximate a normal distribution, we used median regression, a more robust estimation technique under these circumstances. ${ }^{18}$ In general, when the assumptions of a meanbased method are met, mean-based methods are more precise, but when those assumptions are not met, such as in the case of this study where the distribution of the dependent variable is skewed, a median-based method maintains precision better without incurring the disadvantages of potentially arbitrary transformations. ${ }^{19}$

Additionally, we conducted a multivariable median regression analyses of sociodemographic and HIVrelated risk factors for comorbidity outcomes. Variables used included age, smoking status, gender and risk factors for HIV positivity. Risk factors were: men who have sex with men (MSM), injection drug use (IDU), haemophilia and unprotected sex with the opposite sex (USWOS). Because a great deal more data were missing on the two essential variables of years with HIV diagnosis and race/ethnicity, we conducted a regression analysis on the people $(n=2013)$ who had complete data, including those two variables. The regression analysis for the sample with complete data is reported in the main study tables; that of the larger sample with incomplete data is reported in online supplemental digital content table 3. In initial analysis, when we did not test for interactions, we had paradoxical effects wherein people who had quit smoking had worse outcomes than smokers. We probed this effect with the age interaction, viewing age as the closest proxy to how long someone may have smoked. 
Table 1 Frequency of sample characteristics by age group

\begin{tabular}{|c|c|c|c|c|c|c|c|c|c|c|}
\hline & \multicolumn{2}{|c|}{ Under 50} & \multicolumn{2}{|l|}{$50-64$} & \multicolumn{2}{|c|}{$65-74$} & \multicolumn{2}{|c|}{ Over 75} & \multirow[t]{2}{*}{$\rho$} & \multirow[t]{2}{*}{$P$ value } \\
\hline & $\mathrm{n}$ & $\%$ & $\mathrm{n}$ & $\%$ & $\mathrm{n}$ & $\%$ & $\mathrm{n}$ & $\%$ & & \\
\hline Viral load $>200$ & 163 & 14.6 & 113 & 8.4 & 12 & 4.7 & 1 & 2.4 & -0.13 & $<0.001$ \\
\hline Smoking status & & & & & & & & & & $<0.001$ \\
\hline Non-smoker & 554 & 49.6 & 461 & 34.4 & 76 & 30.0 & 15 & 36.6 & & \\
\hline Current smoker & 314 & 28.1 & 369 & 27.6 & 50 & 19.8 & 3 & 7.3 & & \\
\hline Former smoker & 250 & 22.4 & 509 & 38.0 & 127 & 50.2 & 23 & 56.1 & & \\
\hline Gender/sex & & & & & & & & & & $<0.001$ \\
\hline Cismale & 874 & 78.2 & 954 & 71.2 & 177 & 70.0 & 32 & 78.0 & & \\
\hline Cisfemale & 226 & 20.2 & 368 & 27.5 & 74 & 29.2 & 9 & 22.0 & & \\
\hline FTM & 3 & 0.3 & 1 & 0.1 & 0 & 0 & 0 & 0 & & \\
\hline MTF & 15 & 1.3 & 16 & 1.2 & 2 & 0.8 & 0 & 0 & & \\
\hline Risk group & & & & & & & & & & $<0.001$ \\
\hline MSM & 750 & 67.1 & 675 & 50.4 & 96 & 37.9 & 20 & 48.8 & & \\
\hline Injection drug use & 9 & 0.8 & 108 & 8.1 & 35 & 13.8 & 3 & 7.3 & & \\
\hline Haemophilia & 5 & 0.4 & 4 & 0.3 & 0 & 0.0 & 0 & 0.0 & & \\
\hline USWOS & 220 & 19.7 & 408 & 30.5 & 86 & 34.0 & 13 & 31.7 & & \\
\hline MSM+IDU & 24 & 2.1 & 21 & 1.6 & 2 & 0.8 & 0 & 0.0 & & \\
\hline USWOS+IDU & 5 & 0.4 & 71 & 5.3 & 22 & 8.7 & 1 & 2.4 & & \\
\hline Race/ethnicity & & & & & & & & & & 0.007 \\
\hline Other & 160 & 18.7 & 189 & 17.4 & 39 & 18.1 & 5 & 15.2 & & \\
\hline White & 153 & 13.7 & 208 & 15.5 & 47 & 18.6 & 13 & 31.7 & & \\
\hline Hispanic & 260 & 30.4 & 329 & 30.2 & 59 & 27.4 & 6 & 18.2 & & \\
\hline African-American & 267 & 31.3 & 350 & 26.1 & 69 & 27.3 & 9 & 27.3 & & \\
\hline Asian-American & 14 & 1.6 & 13 & 1.2 & 1 & 0.4 & 8 & 19.5 & & \\
\hline \multicolumn{11}{|l|}{ Comorbidity } \\
\hline Multimorbidity & 557 & 49.8 & 1124 & 83.9 & 236 & 93.3 & 40 & 97.6 & 0.45 & $<0.001$ \\
\hline Any comorbidity & 834 & 74.7 & 1282 & 95.7 & 249 & 98.4 & 41 & 100 & 0.35 & $<0.001$ \\
\hline Functional comorbidity & 620 & 55.5 & 1084 & 81.0 & 225 & 88.9 & 41 & 100 & 0.34 & $<0.001$ \\
\hline High-risk comorbidity & 670 & 59.9 & 1166 & 87.1 & 239 & 94.5 & 37 & 90.2 & 0.37 & $<0.001$ \\
\hline Cardiovascular (H) & 267 & 23.9 & 725 & 54.1 & 170 & 67.2 & 32 & 78.0 & 0.37 & $<0.001$ \\
\hline Diabetes $(H)$ & 46 & 4.1 & 254 & 19.0 & 70 & 27.7 & 11 & 26.8 & 0.26 & $<0.001$ \\
\hline Hypertension $(\mathrm{H})$ & 168 & 15.0 & 567 & 42.4 & 161 & 63.6 & 27 & 65.8 & 0.37 & $<0.001$ \\
\hline Kidney disease $(\mathrm{H})$ & 80 & 7.2 & 207 & 15.5 & 83 & 32.8 & 13 & 31.7 & 0.22 & $<0.001$ \\
\hline Cerebrovascular $(\mathrm{H}, \mathrm{F})$ & 17 & 1.5 & 90 & 6.7 & 36 & 14.2 & 12 & 29.3 & 0.19 & $<0.001$ \\
\hline Obesity $(\mathrm{H}, \mathrm{F})$ & 234 & 23.5 & 357 & 26.7 & 54 & 22.3 & 8 & 19.5 & 0.03 & 0.15 \\
\hline Lipohypertrophy/ lipoatrophy $(\mathrm{H}, \mathrm{F})$ & 252 & 22.5 & 416 & 31.1 & 73 & 28.8 & 9 & 22.0 & 0.09 & $<0.001$ \\
\hline Mental health $(F)$ & 390 & 34.9 & 581 & 43.4 & 113 & 44.7 & 18 & 43.9 & 0.10 & $<0.001$ \\
\hline Non-HIV cancer $(\mathrm{H})$ & 4 & 0.4 & 31 & 2.3 & 5 & 2.0 & 3 & 7.3 & 0.09 & $<0.001$ \\
\hline HIV cancer $(\mathrm{H})$ & 54 & 4.8 & 121 & 9.0 & 23 & 9.1 & 3 & 7.3 & 0.09 & $<0.001$ \\
\hline Bone/joint $(F)$ & 33 & 3.0 & 186 & 13.9 & 83 & 32.8 & 13 & 31.7 & 0.30 & $<0.001$ \\
\hline Eye/ear (F) & 127 & 11.4 & 498 & 37.2 & 131 & 51.8 & 28 & 68.3 & 0.37 & $<0.001$ \\
\hline Neurological (F) & 39 & 3.5 & 193 & 14.4 & 62 & 24.5 & 18 & 43.9 & 0.24 & $<0.001$ \\
\hline Anaemia $(\mathrm{H})$ & 235 & 21.8 & 312 & 23.7 & 89 & 35.6 & 16 & 40.0 & 0.08 & $<0.001$ \\
\hline Gastrointestinal (F) & 79 & 7.1 & 117 & 8.7 & 26 & 10.3 & 5 & 12.2 & 0.04 & $<0.001$ \\
\hline Genitourinary (F) & 19 & 1.7 & 174 & 13.0 & 68 & 26.9 & 17 & 41.5 & 0.28 & $<0.001$ \\
\hline COPD/emphysema (H) & 24 & 2.2 & 198 & 8.1 & 39 & 15.4 & 7 & 17.1 & 0.17 & $<0.001$ \\
\hline
\end{tabular}

$\rho$ values (Spearman's correlation) are calculated using age as a continuous variable. $\mathrm{P}$ values for variables with multiple categories are calculated using a multinomial logistic regression.

Multimorbidity is defined as two or more comorbidities. Comorbidity categories: $\mathrm{H}$, high-risk; F, functional.

COPD, chronic Obstructive Pulmonary Disease; FTM, female to male; IDU, injection drug use; MSM, men who have sex with men; MTF, male to female; USWOS, unprotected sex with the opposite sex. 


\section{RESULTS}

For the total sample of 2751 , the median age was 52 years of age (IQR 43-59); $24.6 \%$ of the population identified as female. There were 33 male-to-female and 4 femaleto-male (FTM) transgender individuals, representing $1.4 \%$ of the sample. The population was very racially diverse with Hispanic-Americans (29.9\%) and AfricanAmericans (31.7\%) being well-represented. Most patients in our sample were current $(26.8 \%)$ or former $(33 \%)$ smokers. More than half of those 65 and older were former smokers. The most common risk factor for HIV in our sample was MSM (57.7\%) with unprotected heterosexual sex (USWOS) being the second leading risk factor $(30 \%)$. The median number of years with HIV diagnosis was 19.00 (IQR 11-26).

Table 1 provides the frequency of basic variables, divided into age categories. Viral load was inversely related to age, as was risk of current smoking. In general, race/ethnicity was not related to age, although there was a small increase in likelihood of being white in the older age groups.

Functional and high-risk comorbidities were common in all age groups, but risk increased with age. All patients in the over 75 age group had at least one comorbidity. Multimorbidity, defined as having two or more comorbidities, was very common, affecting nearly half the group under 50 and increasing with age; nearly $100 \%$ of people 75 and older had multimorbidity.

Different comorbidities showed different patterns with age. Some, like cardiovascular disease (CVD), genitourinary disease and hypertension (HTN), demonstrated marked increase in risk with increasing age. Other comorbidities like gastrointestinal disease or cancer demonstrated a weaker link. Mental health problems were highly prevalent in all age groups, slightly more so in older patients. Obesity, although common, showed no relationship to age.

Descriptive statistics for continuous variables in our sample are shown in table 2. Number of comorbidities, as expected, increased with age, starting with a median of 1 $(\mathrm{IQR}=0-3)$ for those under 50 and increasing to a median of 5 (IQR=4-7) in the 75+ age group. Comorbidities of each classification were common, with slightly more high-risk than functional comorbidities in each age category. Although some participants had no comorbidities, the maximum number of comorbidities was 13 inclusive, with 8 in the high risk and 7 in the functional categories.

Median regression results for those with complete data (including race/ethnicity and length of time diagnosed with HIV) are included in table 3 . The beta value describes the change in conditional median number of comorbidities associated with a one unit increase in the variable of interest, with a positive value reflecting an increase, and negative value reflecting a decrease in the conditional median number of comorbidities. The following paragraphs describe the predictors from the different multimorbidity classes. The non-demographic correlates did not differ substantively from the larger population with missing data, as described in online supplemental digital content table 3 except that for high-risk comorbidities, the correlation with having quit smoking reached significance.

\section{All comorbidities}

Associated with a higher number of comorbidities were age $(p<0.001)$, being a cisgender female $(p=0.04)$, being a transgender FTM $(\mathrm{p}=0.04)$, more years with an HIV diagnosis $(\mathrm{p}<0.001)$, being a Hispanic-American $(\mathrm{p}=0.03)$, and being an African-American $(\mathrm{p}<0.001)$. Associated with fewer comorbidities were having the risk factors of MSM $(p<0.001)$ and USWOS $(p=0.009)$. Note in this analysis and for the other comorbidities following, the FTM effect was statistically significant in all three analyses, but there was only one person in the smaller sample.

\section{High-risk comorbidities}

Associated with a higher number of high-risk comorbidities were age $(\mathrm{p}<0.001)$, being a transgender FTM $(p=0.04)$, more years with the diagnosis $(p<0.001)$ and being an African-American $(\mathrm{p}<0.001)$. Associated with fewer comorbidities were having the risk factors of MSM $(p<0.001)$ and IDU $(p=0.007)$. The interaction of age and being a former smoker was also significant $(p=0.001)$ and positive, indicating that the risk from being a former smoker increased with age.

Table 2 HIV parameters and comorbidity types by age category

\begin{tabular}{|c|c|c|c|c|c|c|c|}
\hline & $\begin{array}{l}\text { Total } \\
\text { Median (IQR) }\end{array}$ & $\begin{array}{l}\text { Under } 50 \\
\text { Median (IQR) }\end{array}$ & $\begin{array}{l}50-64 \\
\text { Median (IQR) }\end{array}$ & $\begin{array}{l}65-74 \\
\text { Median (IQR) }\end{array}$ & $\begin{array}{l}\text { 75+ } \\
\text { Median (IQ) }\end{array}$ & $\rho$ & $P$ value \\
\hline Years with HIV diagnosis & $19(11-2)$ & $12(6-19)$ & $22(17-27)$ & $24(19-27)$ & $24(18-29)$ & 0.51 & $<0.001$ \\
\hline Most recent CD4 number & $578(392-783)$ & $584(402-791)$ & $589(388-805)$ & $556(393-712)$ & $523(288-650)$ & -0.04 & 0.02 \\
\hline Most recent CD8 number & $771(536-1048)$ & $761(548-1006)$ & 779 (531-1082) & $788(523-1032)$ & $712(537-1106)$ & 0.01 & 0.57 \\
\hline Functional comorbidity & $1(0-2)$ & $1(0-1)$ & $1(1-2)$ & $3(1-3)$ & $3(2-4)$ & 0.45 & $<0.001$ \\
\hline
\end{tabular}

Data are expressed as median and IQR; $\rho$, Spearman's correlation coefficient. 
Table 3 Multivariable median regressions predicting number of total, high-risk and functional comorbidities for the sample with all demographic variables $(n=2013)$

\begin{tabular}{|c|c|c|c|c|c|c|}
\hline \multirow[b]{2}{*}{ Comorbidity } & \multicolumn{2}{|l|}{ Inclusive } & \multicolumn{2}{|l|}{ High risk } & \multicolumn{2}{|l|}{ Functional } \\
\hline & B (SE) & $P$ value & B (SE) & $P$ value & B (SE) & $P$ value \\
\hline Age (per year) & $0.08(0.01)$ & $<0.001$ & $0.05(0.003)$ & $<0.001$ & $0.04(0.004)$ & $<0.001$ \\
\hline Cisfemale & $0.36(0.18)$ & 0.04 & $-0.15(0.12)$ & 0.21 & $0.39(0.11)$ & $<0.001$ \\
\hline FTM & $3.69(1.82)$ & 0.04 & $2.38(1.16)$ & 0.04 & $1.52(0.51)$ & $<0.001$ \\
\hline \multicolumn{7}{|c|}{ Smoking (reference=non-smoker) } \\
\hline Quit & $0.17(0.12)$ & 0.17 & $0.13(0.09)$ & 0.14 & $0.09(0.08)$ & 0.28 \\
\hline Active & $<0.01(0.15)$ & 0.99 & $0.05(0.10)$ & 0.65 & $-0.02(0.09)$ & 0.83 \\
\hline \multicolumn{7}{|c|}{ Risk factor (no reference) } \\
\hline MSM & $-0.80(0.20)$ & $<0.001$ & $-0.68(0.14)$ & $<0.001$ & $-0.11(0.15)$ & 0.46 \\
\hline Yrs w/Dx & $0.04(0.01)$ & $<0.001$ & $0.02(.005)$ & $<0.001$ & $0.02(0.005)$ & $<0.001$ \\
\hline \multicolumn{7}{|c|}{ Race (reference=white) } \\
\hline Other & $0.04(0.16)$ & 0.79 & $-0.05(0.11)$ & 0.67 & $0.06(0.11)$ & 0.56 \\
\hline Hispanic & $0.34(0.15)$ & 0.03 & $0.02(0.10)$ & 0.85 & $0.20(0.10)$ & 0.01 \\
\hline African-American & $0.60(0.15)$ & $<0.001$ & $0.37(0.11)$ & $<0.001$ & $0.14(0.10)$ & 0.2 \\
\hline Asian-American & $-0.36(0.46)$ & 0.44 & $-0.08(0.23)$ & 0.75 & $-0.42(0.26)$ & 0.1 \\
\hline \multicolumn{7}{|c|}{ Smoking/age Interactions } \\
\hline Quit $\times$ age & $0.01(0.01)$ & 0.31 & $0.02(0.01)$ & $<0.001$ & $0.01(0.01)$ & 0.4 \\
\hline
\end{tabular}

Beta values reflect the effect of the variable on median number of comorbidities. For example, cisfemales have a median 0.36 higher number of comorbidities than cismales; that includes both high risk and functional comorbidities. Beta values for age reflect risk per year of increase in median number of comorbidities.

FTM, female to male; HP, haemophilia; IDU, injection drug use; MSM, men who have sex with men; MTF, male to female; RF, risk factor; USWOS, unprotected sex with the opposite sex; Yrs w/Dx, years with diagnosis.

\section{Functional comorbidities}

Associated with a higher number of functional comorbidities were age $(\mathrm{p}<0.001)$, being a cisgender female $(\mathrm{p}<0.001)$, being a transgender FTM $(\mathrm{p}<0.001)$, being Hispanic $(p<0.01)$ and having more years with an HIV diagnosis $(p<0.001)$. No variables were associated with having fewer number of functional comorbidities.

\section{DISCUSSION}

The risk of individual comorbidities and multimorbidity is higher in people with HIV than in their counterparts without HIV, ${ }^{2-5}$ and the impact of this higher prevalence is not fully understood. In this study, we have used the electronic record of a university-based practice caring for a large, diverse population with HIV and demonstrated that: (1) Comorbidities with primarily functional consequences had a prevalence as high as those with a direct impact on mortality; (2) Different comorbidities had different relationships to age and (3) Although age and number of years with an HIV diagnosis were associated with both high-risk and functional comorbidities as a group, being Hispanic, cisgender female and FTM transgender were associated with functional comorbidities.

Multimorbidity is simple in its fundamental definition, that is, two or more chronic comorbidities, but complex in its meaning. Prevalence of multimorbidity is highly variable and depends on the number of comorbidities under study. For example, Guaraldi $e t a l^{2}$ evaluated people treated at Modena University and included five comorbidities: CVD (combining myocardial infarction, stroke, coronary artery bypass surgery, angioplasty and angina into one category), HTN, diabetes mellitus (DM), renal disease and fractures, and found that the prevalence of multimorbidity was $46.9 \%$ in people with HIV over 60 years of age. Wong $e t a t^{20}$ examined the NA-ACCORD population and restricted their comorbidity list to HTN, DM, chronic kidney disease, hypercholesterolemia, end-stage liver disease and non-AIDS-related cancers, and found a prevalence of multimorbidity in people with HIV 60 and older in 2009 to be $53 \%$. Maggi et al $l^{16}$ evaluated 
eight categories (CVD events, DM, HTN, dyslipidaemia, hepatitis $\mathrm{C}$ antibody positive, psychiatric illness, osteopenia/osteoporosis and renal impairment), and found that $77.1 \%$ of people 60 and older with HIV had multimorbidity. As with these studies, our sample demonstrated high levels of multimorbidity, given the inclusiveness of our definition. Of note, these studies focused largely on high-risk comorbidities (except osteoporosis/fractures and mental health); our study also investigated other, highly prevalent functional comorbidities that have significant impact on quality of life.

Multimorbidity, frailty and mortality are interrelated. ${ }^{21}$ Multimorbidity can be studied to elucidate prognosis as well as aetiology of disease. Multimorbidity has been used to predict mortality and functional decline ${ }^{22} 23$; in these analyses, individual comorbidities are chosen based on impact and are usually assigned weights, the sum of which provides an assessment of risk. Multimorbidity studies have also examined the relationships between comorbidities. In these cases, comorbidities can be grouped together through common etiologies (eg, linkage to obesity), ${ }^{24}$ or used to identify unexpected clusters. ${ }^{1625}$

It is not surprising that in our study age was the strongest driver of most individual comorbidities and multimorbidity. We did note that while age had a strong influence on both functional and high-risk multimorbidity, individual comorbidities demonstrated different age-related patterns. It is likely that obesity and mental health burdens did not change substantially with age as they showed high prevalence in all ages.

Our findings that women had higher multimorbidity burdens than men are also consistent with the literature $^{2627}$ although this seemed to hold only for functional multimorbidity; a recent study also found that women had poorer physical function than men, lending credence to our findings of high functional burden in this group. ${ }^{28}$ We cannot rule out diagnostic bias as a reason why women did not have a higher prevalence of high-risk multimorbidity in our population.

EHR data are incomplete, ${ }^{29} 30$ and there are biases in choosing to evaluate complete records rather than being more inclusive and analysing all records. ${ }^{31}$ We chose to feature those with complete demographic and HIVrelated data because of the importance of these variables. In general, other risk factors for each type of multimorbidity were similar in both the partial and full samples.

Certain findings are surprising. In the high-risk multimorbidity sample, we found that IDU, like MSM, was associated with fewer comorbidities. We do not know if this is related to unknown confounders or biases such as earlier death in the most vulnerable; we also do not know the duration of IDU. This inverse association with IDU did not hold true for functional multimorbidity. In addition, we found that current tobacco use was not associated with greater numbers of both high-risk and functional comorbidities, although having quit was associated with increased risk in the full sample. We do not know how many pack-years patients in this cohort have smoked, or when they quit. There was an interaction between having quit and age for those with high-risk multimorbidity, and we suspect that older smokers may have been more likely to quit because of poor health. This may explain the paradoxical finding that having quit smoking correlated with high-risk comorbidity. Rather, those who are older may not have benefited from having quit smoking and yet may still carry the risk of many years of tobacco use.

We were interested in comorbidity as encountered by the clinician, not as a predictive measure. Overall comorbidity burden has an impact on both mortality and function, ${ }^{23}$ and our decision to divide comorbidities into those with mortality and functional impact was not designed for prognostic purposes; instead it was designed from the clinician's perspective, in directing attention and resources to patients and subpopulations. The clinic population is large and diverse, and our findings are generalisable to the larger population with HIV: The significant burden of functional multimorbidity described in this study highlights the importance of acknowledging and addressing this burden.

There are a number of limitations to this study. It is from a single academic medical centre in New York City, but its size and the diversity of its population compensate to a large degree. It is based on automated extraction of ICD-10 codes and labs from an EHR; neither patient interview nor note review was possible to add missing data, making it likely that some comorbidities, particularly arthritis, were underestimated. ${ }^{23}$ Geriatric syndromes like frailty or social stressors like loneliness are rarely coded as ICD-10 diagnoses and are also missing from the analysis. In addition, ICD-10 codes were extracted from the past medical history, surgical history and problem list, and these are only as accurate as the providers maintaining them. Because of this, there is no method to determine if a problem was resolved or considered active. Another limitation of this study is the lack of literature classifying comorbidities; for this reason, the authors determined which comorbidities would fall into the functional and high-risk classification groups; while these were determined a priori, there may be some unknown bias in the choices. There were insufficient data about socioeconomic status to add these data to the analysis, and this may have resulted in unknown confounding. Finally, we cannot rule out diagnostic bias as a reason for differences in morbidity prevalence in different demographic groups.

\section{CONCLUSIONS}

In our large sample of adults with HIV, we found significant burdens of functional multimorbidity in addition to high-risk comorbidities. Diseases that have an impact on function are highly prevalent and increase with age; they likely are additive to the more commonly recognised comorbidities seen in this population and may have a significant impact on quality of life. Future research is needed to better define and catalogue functional comorbidities, understand how they cluster and who is at highest 
risk for them, and assess their impact on people ageing with HIV.

Acknowledgements We acknowledge the assistance of Erik Ross in retrieval and refinement of the database.

Contributors ES: design, acquisition, analysis, data interpretation; drafting and revision of manuscript. JM: design, analysis, data interpretation, revision of manuscript. EM: design, analysis, revision of manuscript. MG: design, acquisition, analysis, data interpretation, drafting and revision of manuscript.

Funding EM, MS, was partially supported by the National Center for Advancing Translational Science of the National Institutes of Health under Award Number 1-UL1TR002384. ES receives support from the Wayen Family Charitable Foundation

Competing interests MG reports research support to Weill Cornell Medicine from Gilead Sciences and Regeneron; royalties from Springer and UpToDate. He is a consultant to ReAlta Life Sciences, Regeneron and Sobi. ES has received research support to Weill Cornell Medicine from Gilead Sciences.

Patient consent for publication Not required.

Ethics approval The Weill Cornell Medicine Institutional Review Board (IRB \# 1505016187) approved this study. This was a retrospective study involving chart data from thousands of participants. Informed consent requirement was waived by the IRB.

Provenance and peer review Not commissioned; externally peer reviewed.

Data availability statement Data are available on reasonable request. Data can be made available by emailing the corresponding author.

Supplemental material This content has been supplied by the author(s). It has not been vetted by BMJ Publishing Group Limited (BMJ) and may not have been peer-reviewed. Any opinions or recommendations discussed are solely those of the author(s) and are not endorsed by BMJ. BMJ disclaims all liability and responsibility arising from any reliance placed on the content. Where the content includes any translated material, BMJ does not warrant the accuracy and reliability of the translations (including but not limited to local regulations, clinical guidelines, terminology, drug names and drug dosages), and is not responsible for any error and/or omissions arising from translation and adaptation or otherwise.

Open access This is an open access article distributed in accordance with the Creative Commons Attribution Non Commercial (CC BY-NC 4.0) license, which permits others to distribute, remix, adapt, build upon this work non-commercially, and license their derivative works on different terms, provided the original work is properly cited, appropriate credit is given, any changes made indicated, and the use is non-commercial. See: http://creativecommons.org/licenses/by-nc/4.0/.

\section{ORCID iDs}

Eugenia Siegler http://orcid.org/0000-0001-9449-5873

Jerad Moxley http://orcid.org/0000-0002-4362-9963

Elizabeth Mauer http://orcid.org/0000-0003-2870-7377

Marshall Glesby http://orcid.org/0000-0002-2145-148X

\section{REFERENCES}

1 Wandeler G, Johnson LF, Egger M. Trends in life expectancy of HIV-positive adults on antiretroviral therapy across the globe: comparisons with general population. Curr Opin HIV AIDS 2016;11:492-500.

2 Guaraldi G, Orlando G, Zona S, et al. Premature age-related comorbidities among HIV-infected persons compared with the general population. Clin Infect Dis 2011;53:1120-6.

3 Schouten J, Wit FW, Stolte IG, et al. Cross-sectional comparison of the prevalence of age-associated comorbidities and their risk factors between HIV-infected and uninfected individuals: the AGEhIV cohort study. Clin Infect Dis 2014;59:1787-97.

4 Kong AM, Pozen A, Anastos K, et al. Non-HIV comorbid conditions and polypharmacy among people living with HIV age 65 or older compared with HIV-negative individuals age 65 or older in the United States: a retrospective Claims-Based analysis. AIDS Patient Care STDS 2019;33:93-103.
5 d'Arminio Monforte A, Bonnet F, Bucher HC, et al. What do the changing patterns of comorbidity burden in people living with HIV mean for long-term management? Perspectives from European HIV cohorts. HIV Med 2020;21:3-16.

6 Triant VA, Grinspoon SK. Epidemiology of ischemic heart disease in HIV. Curr Opin HIV AIDS 2017;12:540-7.

7 McComsey GA, Tebas P, Shane E, et al. Bone disease in HIV infection: a practical review and recommendations for HIV care providers. Clin Infect Dis 2010;51:937-46.

8 Nanni MG, Caruso R, Mitchell AJ, et al. Depression in HIV infected patients: a review. Curr Psychiatry Rep 2015;17:1-11.

9 Greene M, Covinsky KE, Valcour V, et al. Geriatric syndromes in older HIV-infected adults. J Acquir Immune Defic Syndr 2015;69:161-7.

10 Singh HK, Del Carmen T, Freeman R, et al. From one syndrome to many: incorporating geriatric consultation into HIV care. Clin Infect Dis 2017;65:501-6.

11 World Health Organization. World report on ageing and health, 2015. Available: http://www.who.int/ageing/publications/world-report-2015/ en/ [Accessed 20 Feb 2021].

12 van den Akker M, Buntinx F, Knottnerus JA. Comorbidity or multimorbidity: what's in a name? A review of literature. Europ $\mathrm{J}$ Gen Pract 1996;2:65-70.

13 Guaraldi G, Malagoli A, Calcagno A, et al. The increasing burden and complexity of multi-morbidity and polypharmacy in geriatric HIV patients: a cross sectional study of people aged $65-74$ years and more than 75 years. BMC Geriatr 2018;18:99.

14 Salter ML, Lau B, Go VF, et al. HIV infection, immune suppression, and uncontrolled viremia are associated with increased multimorbidity among aging injection drug users. Clin Infect Dis 2011;53:1256-64.

15 Diederichs C, Berger K, Bartels DB. The measurement of multiple chronic diseases--a systematic review on existing multimorbidity indices. J Gerontol A Biol Sci Med Sci 2011;66:301-11.

16 Maggi P, Santoro CR, Nofri M, et al. Clusterization of co-morbidities and multi-morbidities among persons living with HIV: a crosssectional study. BMC Infect Dis 2019;19:555.

17 Richesson RL, Horvath MM, Rusincovitch SA. Clinical research informatics and electronic health record data. Yearb Med Inform 2014;9:215-23.

18 Koenker R. Quantile regression. Cambridge: Cambridge University Presss, 2005.

19 Huber PJ, Rochetti EM. Robust statistics. Hoboken, NJ: Wiley, 2009.

20 Wong C, Gange SJ, Moore RD, et al. Multimorbidity among persons living with human immunodeficiency virus in the United States. Clin Infect Dis 2018;66:1230-8.

21 McMillan JM, Krentz HB, Gill MJ, et al. An emerging concern-high rates of frailty among middle-aged and older individuals living with HIV. Can Geriatr J 2019;22:190-8.

$22 \mathrm{Xu} \mathrm{X,} \mathrm{Mishra} \mathrm{GD,} \mathrm{Jones} \mathrm{M.} \mathrm{Evidence} \mathrm{on} \mathrm{multimorbidity} \mathrm{from}$ definition to intervention: an overview of systematic reviews. Ageing Res Rev 2017;37:53-68.

23 Wei MY, Ratz D, Mukamal KJ. Multimorbidity in medicare beneficiaries: performance of an ICD-coded multimorbidity-weighted index. J Am Geriatr Soc 2020;68:999-1006.

$24 \mathrm{Kim}$ DJ, Westfall AO, Chamot E, et al. Multimorbidity patterns in HIVinfected patients: the role of obesity in chronic disease clustering. $J$ Acquir Immune Defic Syndr 2012;61:600-5.

25 De Francesco D, Sabin CA, Reiss P. Multimorbidity patterns in people with HIV. Curr Opin HIV AIDS 2020;15:110-7.

26 Castilho JL, Escuder MM, Veloso V, et al. Trends and predictors of non-communicable disease multimorbidity among adults living with HIV and receiving antiretroviral therapy in Brazil. J Int AIDS Soc 2019;22:e25233.

27 Palella FJ, Hart R, Armon C, et al. Non-AIDS comorbidity burden differs by sex, race, and insurance type in aging adults in HIV care. AIDS 2019;33:2327-35.

28 Brañas F, Sánchez-Conde M, Carli F, et al. Sex differences in people aging with HIV. J Acquir Immune Defic Syndr 2020;83:284-91.

29 Madden JM, Lakoma MD, Rusinak D, et al. Missing clinical and behavioral health data in a large electronic health record (EHR) system. J Am Med Inform Assoc 2016;23:1143-9.

30 Weiskopf NG, Hripcsak G, Swaminathan S, et al. Defining and measuring completeness of electronic health records for secondary use. J Biomed Inform 2013;46:830-6.

31 Weber GM, Adams WG, Bernstam EV, et al. Biases introduced by filtering electronic health records for patients with "complete data". J Am Med Inform Assoc 2017;24:1134-41. 